\title{
Research on the Impact of the Belt and Road Initiative Development Index and China's Foreign Direct Investment
}

\author{
Xuemei, Li ${ }^{[1]}$, JiePeng $^{[2]}$, Xiaojun,Zhao $^{[3]}$ \\ Department of Economics, Beijing Jiaotong University, Beijing, China \\ email: 16120520@bjtu.edu.cn
}

Keywords: Belt and Road; infrastructure index; foreign direct investment; threshold effect

\begin{abstract}
This paper is devoted to comprehensive assessment of infrastructure development in 42 countries along the "Belt and Road" from different dimensions, including transportation infrastructure, communication network infrastructure, education infrastructure, and energy infrastructure, according to its economic and social development status, build national infrastructure development index along the "Belt and Road". Focusing on the changing trend of representative countries' infrastructure development index from the time dimension, horizontally comparing the level of infrastructure development along the "Belt and Road" countries, and finally discussing the impact of different dimensions of infrastructure development index and China's direct investment in countries along the "Belt and Road", the conclusion shows that there is a threshold effect.

\section{“一带一路”基础设施发展指数与中国对外直接投资影响研究}

\author{
李雪梅 ${ }^{[1]}$,彭洁 ${ }^{[2]}$,赵晓军 ${ }^{[3]}$ \\ 1 北京交通大学经济系, 北京, 中国 \\ 通讯作者:彭洁
}

关键词：一带一路；基础设施指数；对外直接投资；门槛效应

摘要：本文致力于从不同维度对 “一带一路” 沿线 42 个国家的基础设施发展情况进行综合 评估, 包括交通基础设施、通信网络基础设施、教育基础设施、能源基础设施, 根据其经济 社会的发展现状，构建 “一带一路” 沿线国家基础设施发展指数。从时间维度关注代表性国 家基础设施发展指数的变化趋势, 横向比较各 “一带一路” 沿线国家基础设施发展水平, 最 后讨论不同维度基础设施发展指数与中国对 “一带一路” 沿线国家直接投资的影响关系, 结 论表明存在门槛效应。

\section{1. 引言}

2013 年, 习近平主席在访问哈萨克斯坦和印度尼西亚时, 分别提出建设 “丝绸之路经济 带” 和 “21 世纪海上丝绸之路” 合作倡议。五年来，在各国的共同努力下，“一带一路”从 倡议变为现实, 从经贸往来的商路, 连接起彼此人民的心路, “一带一路” 战略对中国的发 展也将进入全面推进建设阶段。2003 到 2015 年期间我国对 “一带一路” 沿线国家的直接投资 呈现稳步上升的趋势, 2016 年虽然有所下降，但从 2003 年 19239 万美元到 2016 年 1533936 万美元, 增长了近 80 倍。虽然我国对 “一带一路” 国家的直接投资有着显著的增长, 但由于 周边国家的经济发展不平衡, 彼此之间联系不紧密, 各项基础设施分布严重不均, 难以满足 经贸合作的要求, 成为制约区域经济合作的一大短板。同时各国的交通、通讯、能源、教育 等基础设施水平存在显著差异，加大了我国对外直接投资的风险，使得我国对 “一带一路” 
国家的基础设施投资项目以及其他项目出现巨大损失。因而有必要将基础设施细化，从而分 别测算不同类型的基础设施对我国对外直接投资的影响。

本论文旨在制定 “一带一路”综合发展评价体系，基于搭建 “一带一路”综合发展评价指 标体系框架，构建 “一带一路” 综合发展指数，并讨论不同维度下的基础设施发展指数在时 间、国别以及区域上的差异，最终讨论基础设施综合指数与中国对 “一带一路” 国家直接投 资的关系。

\section{2. 文献综述}

现有文献部分从运输成本的角度，探讨了基础设施对出口贸易和对外直接投资的影响， 基础设施数量和质量的差异可能会导致运输成本的不同，并且国家间运输成本的不同也会造 成其在国际市场上竞争能力的差异。大多数观点认为基础设施发展水平在很大程度上是运输 成本和双边贸易的主要决定因素。(Bougheas, 1999; Venables, 2001; Edwards, Odendaal, 2008）。在出口贸易的研究领域中, 基础设施一直以来都是重要的影响因素。同样在吸引外商 投资方面，基础设施的完善程度对外商投资区位选择具有重要影响，大多数研究结果表明基 础设施的发展对吸引外商投资呈现正向作用。基础设施水平越高, 越能形成集聚经济, 贸易 成本也越低, 从而吸引外商投资。(郑荷芬、马淑琴等 2013; 王晓东、邓丹营, 2014; Kumar, 2001)

部分学者从 “新经济地理学” 的角度研究对外直接投资的影响因素，研究表明规模报酬 递增、市场结构不完全、贸易成本、地区需求内生化、关税、贸易距离、基础设施水平等都 对对外直接投资区位选择有着显著的影响。基础设施投资在总体上有利于东道国经济增长, 对外直接投资也可以促进产业集聚的形成。同时，国内学者从新经济地理因素、传统经济因 素、制度因素三大方面研究对外直接投资区位选择，研究发现对外投资会倾向于流入己有投 资规模较大的国家或地区，同时会倾向于流入贸易成本较低的国家或地区，市场规模吸引投资 的正向作用被较高的运输成本抵消, 而且经济开放程度和双边投资协定均存在积极影响。另外， 交通基础设施通过提高出口比较优势、加快区域市场整合以及促进经济活动集聚等影响机理 来实现其对制造业生产率增长的空间溢出效应, 是影响产业集聚的主要因素, 从而对对外投 资产生影响。(Krugman, 1991; Mucchie11i, Louis J, 2004; Amiti，2001)

然而有部分研究表明东道国基础设施的改善并不显著影响外资的流入，一方面由于东道 主国家基础设施水平过于落后，经济社会环境动荡，使得对外投资产生了巨大的风险性; 另 一方面当一个国家基础设施发展水平较高时，国家之间的对外直接投资会产生竞争和挤出效 应, 从而使得基础设施与对外投资之间的关系不显著。(Mudambi, 1995; Asiedu, 2002; Quazi, 2005; Chan, 2014; 崔岩，于津平，2017）

综上所述: 基础设施的良好发展可以从交通、能源、通信、教育等多个维度减轻贸易的运 输成本、生产成本、沟通成本、人才培训成本，能够加深企业和市场的联系，使得信息收集 便利度提高，贸易成本降低，形成产业集聚。基础设施的良好水平也会促进外商投资企业的 生产率，降低投资成本，最终吸引他国投资。另外，部分国家由于基础设施水平过于落后， 经济社会环境动荡，使得中国对这类国家的直接投资产生了巨大的风险性，当部分国家基础 设施发展水平超过一定的程度后, 国家之间的对外直接投资可能会产生竞争效应和挤出效应, 从而可能对吸引外国投资产生反向的抑制作用，对于 “一带一路” 国家来说，由于经济发展 的巨大差异性以及基础设施发展水平的不平衡性，很难从理论上断定基础设施与对外直接投 资的沿线关系一定是正向的，需要有实证检验的支撑。而在对 “一带一路” 沿线国家直接投 资影响因素的研究中，大多数文献对 “一带一路” 沿线国家直接投资的描述性分析居多，定 量分析不足，尤其是研究 “一带一路” 沿线国家基础设施发展水平与中国的对外直接投资这 方面不够充分。涉及到基础设施发展与对外直接投资影响实证研究的论文，也只是把基础设 施作为一个影响变量, 忽略了不同维度的基础设施发展水平的差异性。与以往研究相比, 本 
文的不同之处在于：第一，聚焦 “一带一路” 国家，在数据可获取的前提下，尽量将足够多 的国家纳入研究范围之内; 第二, 不再用单一指标作为衡量基础设施发展水平, 而是采用一 系列有代表性的指标, 利用熵权法加权算得综合性的指数; 第三, 从多个维度分析基础设施 发展水平与对外直接投资之间的关系，并从时间、国别和区域角度分析其差异性。

\section{3. “一带一路” 基础设施发展指数的影响因素指标化分析}

\section{1. 指标集选取}

指标选取采取科学性、系统性、代表性、可操作性以及数据的可得性等原则。本文从多 个维度选取 “一带一路” 基础设施发展水平指标。与传统的基础设施发展指数不同, 其研究 边界多为相对独立、地位对等的国家内部或地区之间。“一带一路” 基础设施发展指数研究 边界覆盖联系紧密的多个经济体, 沿线国家与地区社会经济发展水平极不均衡, 经济规模差 异巨大，基础设施发展水平也各不相同，文化，政策、贸易、资金等也存在明显差异，因此， “一带一路”基础设施发展指数选取相对指标，进行系统合理评价，具体指标如表 1 。

表 1 “一带一路”国家基础设施发展水平指标集

\begin{tabular}{|c|c|c|}
\hline 一级指标 & 二级指标 & 三级指标 \\
\hline \multirow{14}{*}{$\begin{array}{l}\text { 基 } \\
\text { 础 } \\
\text { 设 } \\
\text { 施 } \\
\text { 发 } \\
\text { 展 } \\
\text { 水 } \\
\text { 平 } \\
\text { 指 } \\
\text { 数 }\end{array}$} & \multirow{5}{*}{ 交通基础设施 } & 铁路路网密度（公里/平方公里） \\
\hline & & 公路路网密度（公里/平方公里） \\
\hline & & 航空客运量（人） \\
\hline & & 港口基础设施质量(WEF, $1=$ 十分欠发达至 \\
\hline & & 7=根据国际标准，十分发达高效） \\
\hline & \multirow{4}{*}{ 能源基础设施 } & 人均石油使用量(千克) \\
\hline & & 人均耗电量(千瓦时) \\
\hline & & 燃气普及率 \\
\hline & & 固定电话用户数（每百人） \\
\hline & \multirow[t]{2}{*}{ 通讯基础设施 } & 移动电话用户数（每百人） \\
\hline & & 安全互联网服务器（每百万人） \\
\hline & \multirow{3}{*}{ 教育基础设施 } & 人均教育开支额 \\
\hline & & 高等院校入学率 \\
\hline & & 平均初等教育教师数目(/万人) \\
\hline
\end{tabular}

\section{2. 数据处理过程}

文章对外直接投资数据来自中国2003-2016对外直接投资统计公报，构建不同维度基础设 施发展指数采用的数据来自世界银行数据库、国际贸易组织等, 时间跨度选择为 $1960-2016$ 年。 由于我国对 “一带一路” 沿线国家直接投资数据缺失值较为严重, 最终选择了 42 个国家作为 样本数据进行研究。对于缺失值处理部分, 利用R语言软件运用均值插补、时间序列法、多重 插补法等三种方法进行填充, 确保数据的科学, 真实, 有效性。在数据采集过程中, 不同的 指数存在统计口径不一致、数据不公开等因素，会导致指标间往往会造成几个数量级之间的 
差异, 因此在计算基础设施发展指数前, 需要对原始数据进行归一化。由于本文使用的指标 都是正向性指标，采用的数据归一化方法如下:

$$
X_{i j}=\frac{\operatorname{Max}\left(X_{j}\right)-X_{i j}}{\operatorname{Max}\left(X_{j}\right)-\operatorname{Min}\left(X_{j}\right)}
$$

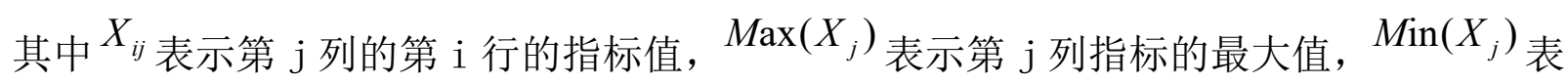
示第 $i$ 列指标的最小值。最后运用熵权法, 算出不同维度下 “一带一路” 沿线各国基础设施 发展指数并排名。

\section{4. “一带一路” 基础设施发展指数分析}

通过计算，“一带一路”沿线 42 个国家的能源、交通、通信、教育基础设施得分排名前 10 情况如表 2 。从能源基础设施发展情况来看, 排名前 10 的国家包括西亚北非地区的阿拉伯 国家 2 个(科威特，卡特尔)，这部分国家能源资源丰富，石油，天然气工业为国民经济的支 柱型产业。中东欧国家 4 个(波兰，捷克共和国，俄罗斯，保加利亚），这部分国家石油资源 相对丰富, 天然气资源较少，人均耗电量也仅次于阿拉伯国家。中亚及蒙古地区国家 2 个(蒙 古, 哈萨克斯坦), 蒙古和哈萨克斯坦煤炭资源丰富, 已探明的煤炭存储量分别位列全球第七 与第八，且 2016 年煤炭量发电的比例分别占总发电比例的 94. 89\%和 73. 13\%。从交通基础设 施来看，中东欧发达国家前 10 排名占据 4 位，包括捷克共和国、匈牙利、波兰。中东欧国家 经济发达, 铁路建设完善, 铁网密度很大, 航空客运量也位居前列。东南亚国家则包括印度 尼西亚、泰国、马来西亚等国, 这部分国家注重旅游业的发展, 吸引国外游客发展经济, 其 航空客运量人数较多, 并且其港口基础设施的质量 (WEF) 也较好。对于通信基础设施, 以新加 坡为首的发达国家占据了大多数，包括捷克共和国、以色列、文莱、匈牙利、波兰等。这些 国家的安全互联网普及率高, 通信设备完善, 移动电话每百人普及率基本都超过了 $50 \%$ 。最后 关于教育基础设施, 西亚北非 4 国占据了教育基础设施的前 4 名, 最重要的原因是这些国家 的人均教育投资额远远高于其他国家，达到了 1404.23 美元/人。教育基础设施发展较好的国 家还包括新加坡、波兰、文莱等国, 说明经济实力雄厚的发达国家对于教育方面的重视程度 要高于东南亚, 南亚以及中亚地区的发展中国家。

表 2 “一带一路” 沿线 42 个国家不同维度下基础设施发展指数得分前 10

\begin{tabular}{|c|c|c|c|c|c|c|c|c|}
\hline \multicolumn{3}{|c|}{ 能源基础设施 } & \multicolumn{2}{|c|}{ 交通基础设施 } & \multicolumn{2}{|c|}{ 通信基础设施 } & \multicolumn{2}{|c|}{ 教育基础设施 } \\
\hline 排名 & 国家 & 得分 & 国家 & 得分 & 国家 & 得分 & 国家 & 得分 \\
\hline 1 & 卡塔尔 & 100.00 & 捷克 & 100.00 & 新加坡 & 100.00 & 卡特尔 & 100.00 \\
\hline 2 & 波兰 & 77.61 & 俄罗斯 & 93.78 & 捷克 & 73.66 & 以色列 & 83.65 \\
\hline 3 & 捷克 & 72.56 & 印度 & 86.30 & 以色列 & 68.37 & 科威特 & 66.92 \\
\hline 4 & 哈萨克斯坦 & 72.40 & 匈牙利 & 76.81 & 波兰 & 48.41 & 沙特阿拉伯 & 60.56 \\
\hline 5 & 蒙古 & 70.02 & 印尼 & 64.38 & 匈牙利 & 41.58 & 文莱 & 52.30 \\
\hline 6 & 科威特 & 66.08 & 波兰 & 63.70 & 卡塔尔 & 32.80 & 新加坡 & 43.71 \\
\hline 7 & 文莱 & 63.17 & 土耳其 & 62.96 & 保加利亚 & 32.37 & 波兰 & 42.20 \\
\hline 8 & 以色列 & 57.79 & 马来西亚 & 53. 13 & 科威特 & 31.84 & 俄罗斯 & 39.20 \\
\hline 9 & 俄罗斯 & 52.41 & 泰国 & 51.16 & 文莱 & 26.68 & 匈牙利 & 38.65 \\
\hline 10 & 保加利亚 & 50.98 & 以色列 & 43.38 & 俄罗斯 & 23.60 & 捷克 & 38.07 \\
\hline
\end{tabular}




\section{5. “一带一路” 基础设施发展水平变化趋势与对外直接投资}

将 “一带一路” 沿线 42 个国家 1960-2016 年得分按照区域汇总后取平均, 得到图 1。可 以看出, 中东欧在能源基础设施、交通基础设施以及通信基础设施的建设方面相对其他区域 有很明显的优势, 一方面是由于中东欧国家经济比较发达, 另一方面中亚, 南亚还处于赶超 期, 基础设施的建设与发展还有很长的路要走。南亚在教育基础设施、能源基础设施、通信 基础设施相对其他区域评分最低，但其交通基础设施得分却排名第二，且相对评分有上升的 趋势, 这与南亚国家经济主体侧重方面有关, 南亚国家是世界上人口最多和最密集的区域, 相对而言比较贫穷, 主要发展农业与旅游业, 铁网密度和航空客运量都要高于西亚北非国家 和东南亚国家。能源基础设施方面, 虽然得分排名前 10 中有科威特、卡塔尔、以色列等西亚 北非国家, 但是其总体的能源基础设施得分却并不是特别靠前, 这是因为西亚北非等阿拉伯 国家政治局势不明朗, 战乱频繁。包括叙利亚、阿富汗、伊拉克在内的西亚北非国家在能源 基础设施得分很低，拉低了西亚北非的整体评分。

整体来说，从 1960-2016 年“一带一路” 沿线区域在基础设施发展方面，虽然有所波动， 但整体的相对变化趋势不是很大。中东欧的各项基础设施都处于领先地位, 西亚地区教育基 础设施上较为突出, 其通信基础设施与能源基础设施位于中等, 交通基础设施则相对薄弱。 中亚地区能源基础设施相对得分处于第二，但其交通、通信基础设施远远落后于其他区域。 追赶最快的区域当属东南亚, 其交通、教育、能源以及通信都呈现逐年上升的趋势, 虽然与 中东欧等国家仍然有较大差距, 但其基础设施水平的发展比较迅猛, 整体上升趋势也比其他 区域快。
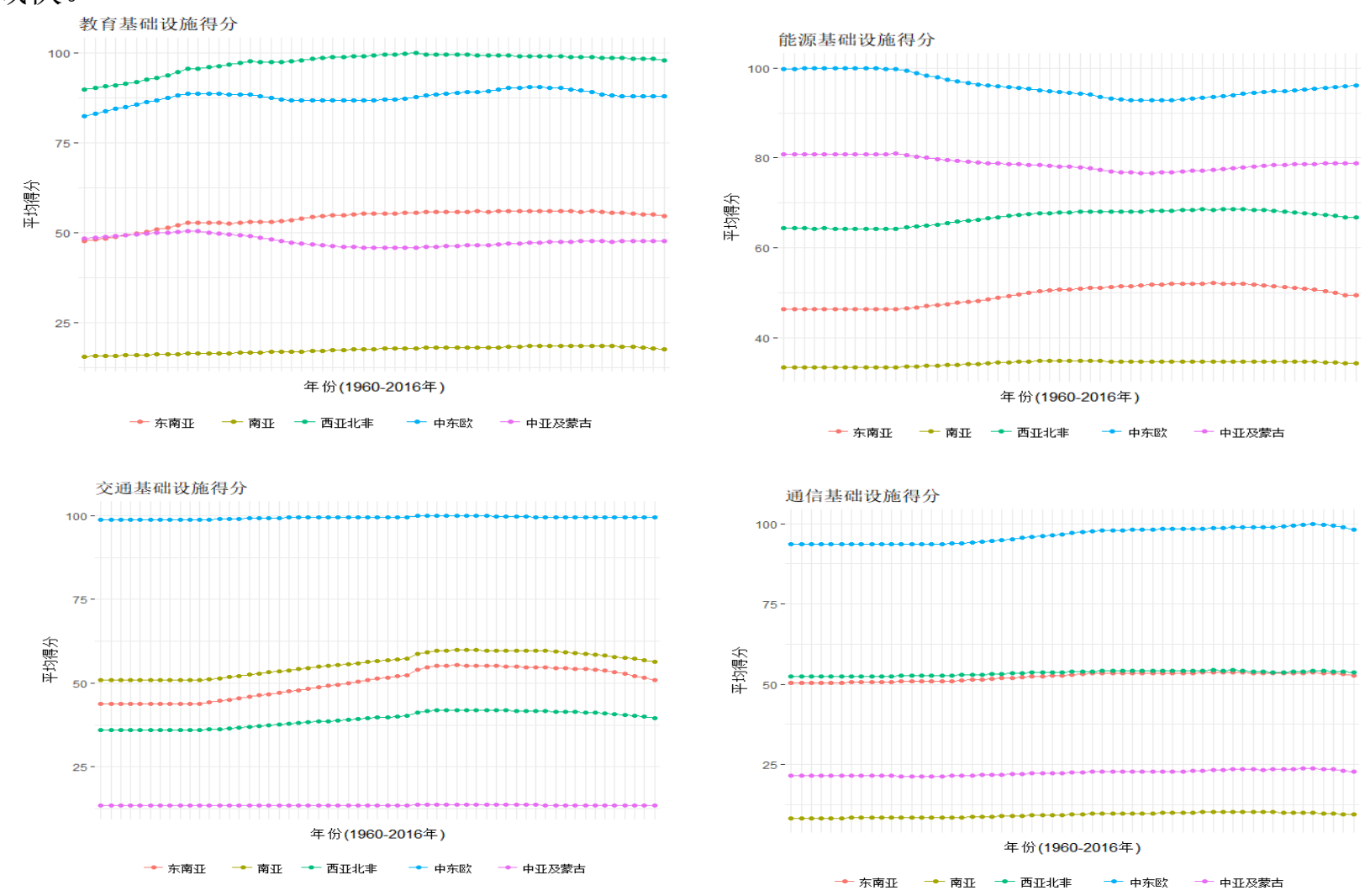

图 1 1960-2016 年各区域基础设施发展水平得分相对情况变化图

根据测算得到不同维度的基础设施发展指数，运用加权局部回归(1ocally weighted regression) 法画出中国对 “一带一路” 沿线 42 个国家直接投资与基础设施发展指数散点图 (图 2)。可以看出：对于教育、能源、交通基础设施而言, 刚开始随着基础设施的不断完 善, 对外直接投资呈现正相关, 当达到某一临界点之后, 对外直接投资则开始下滑。对于教 育而言, 随着教育的初步发展, 员工的素质, 工作效率得到提升从而能够吸引中国投资, 而 
当教育发展到一定程度, 劳动力成本上升, 人口红利萎缩, 对吸引对外直接投资则产生了抑 制作用。对于能源与交通来说, 随着能源、交通基础设施的不断完善, 生产成本, 运输成本 都会降低, 从而吸引中国对其投资, 但达到一定的水平之后, 其他外来投资国也会对其进行 投资，从而对中国的投资可能会产生竞争效应和挤出效应，最终也会抑制中国对其投资。通 信基础设施则呈现不同的趋势, 刚开始随着通信基础设施的提高, 对外直接投资的吸引力提 升不大, 当达到一定临界点的后, 两者呈现指数型的上升关系, 通信基础设施的快速发展能 够提升工作效率，减少沟通成本，提升决策质量，吸引对外直接投资。
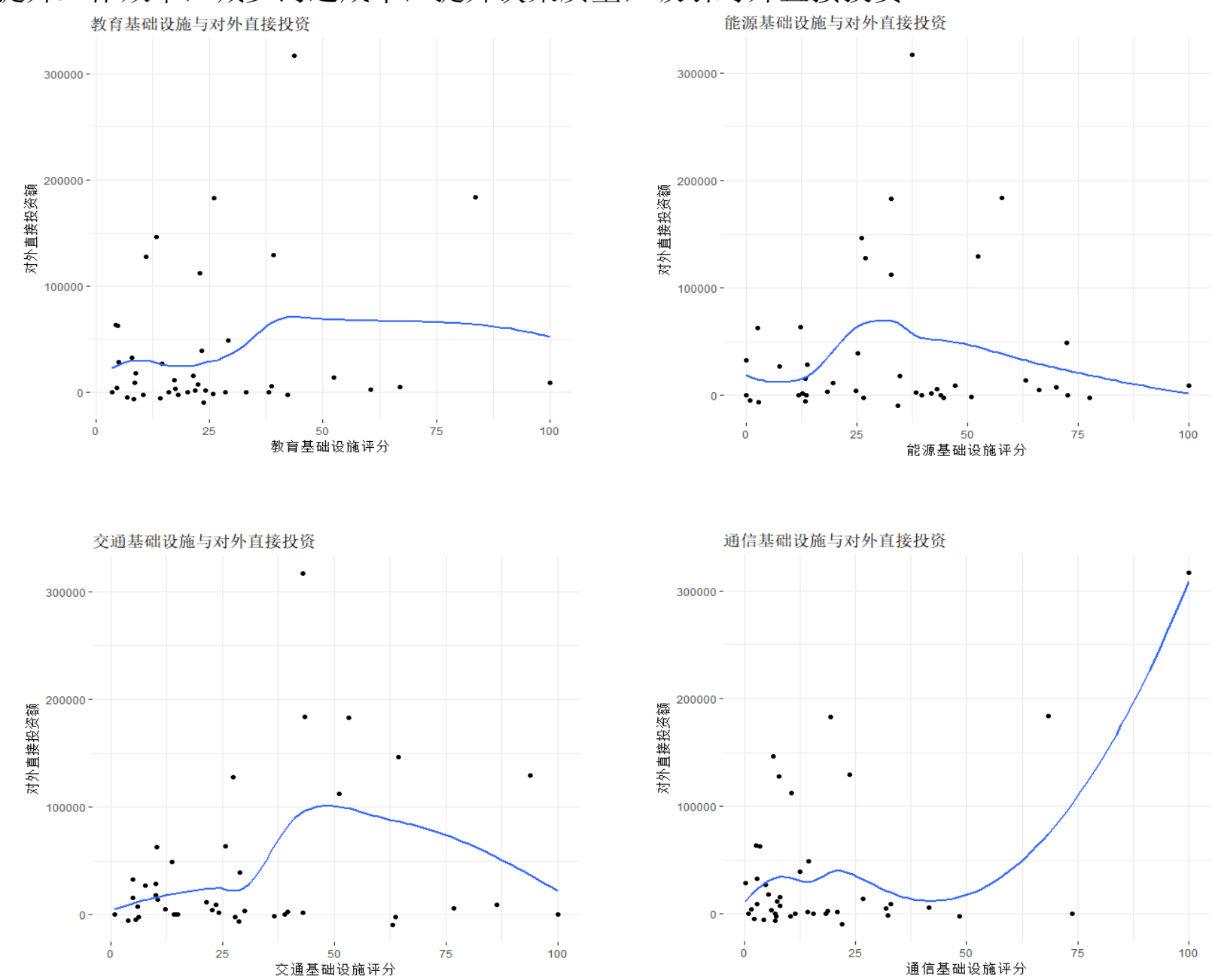

图 2 基础设施发展指数与对外直接投资散点图

\section{6. 结语}

基础设施互联互通是 “一带一路” 和谐发展的基石，构建 “一带一路” 基础设施综合发 展指数有助于中国企业在总体上从不同的角度把握各国的基础设施发展现状，为 “走出去” 提供科学合理的依据。本文从多个角度考虑 “一带一路” 沿线 42 个国家的基础设施发展状 况, 并从区域的视角研究了近 56 年来基础设施发展的相对情况, 最终利用 1oess 局部加权 回归分析了各维度基础设施指数与对外直接投资的门槛效应，为中国企业提供了参考。

\section{致谢}

本文为基本科研业务费项目《“一带一路” 基础设施网络：现状、需求与潜力》（原项 目编号 2017JBZ005) 的阶段性成果之一。 


\section{References}

[1] Bougheas S, Demetriades P O, Morgenroth E L W. Infrastructure, transport costs and trade[J]. Journal of International Economics, 1999, 47(1):169-189.

[2] Venables A J. Infrastructure, Geographical Disadvantage, Transport Costs, and Trade[J]. World Bank Economic Review, 2001, 15(3):451-479.

[3] Edwards L, Odendaal M. Infrastructure, Transport Costs and Trade: A New Approach[J].

[4] Zheng Hefen, Ma Shuqin, Xu Yingxia. Empirical Study on the Impact of Infrastructure Input on Service Trade Structure_Evidence from Multinational Panel Data[J]. International Trade Problem, 2013(5): 115-127.

[5] Wang Xiaodong, Deng Danwei, Zhao Zhongxiu. Impact of Transportation Infrastructure on Economic Growth__ An Empirical Test Based on Provincial Panel Data and Feder Model[J]. Management World, 2014(4): 173-174.

[6] Kumar N. Infrastructure availability, foreign direct investment inflows and their exportorientation: a cross-country exploration[J]. 2001.

[7] Krugman P. Increasing Returns and Economic Geography[J]. Nber Working Papers, 1991, 99(3):483-499.

[8] Mucchielli, Louis J. Multinational Firms' Location and the New Economic Geography[M]. Multinational firms' location and the new economic geography . Edward Elgar, 2004:579-581.

[9] Amiti M. Location of vertically linked industries: agglomeration versus comparative advantage [J]. European Economic Review, 2001, 49(4):809-832.

[10]Mudambi R. The MNE Investment Location Decision: Some Empirical Evidence[J]. Managerial \& Decision Economics, 1995, 16(3):249-257.

[11]Asiedu E. On the Determinants of Foreign Direct Investment to Developing Countries: Is Africa Different[J]. World Development, 2002, 30(1):107-119.

[12]Rahim Quazi. Economic Freedom and Foreign Direct Investment in East Asia[J]. Journal of the Asia Pacific Economy, 2007, 12(3):329-344.

[13]Cui Yan, Yu Jinping. National Infrastructure Quality of China, China, and China's Foreign Direct Investment: A Study Based on Panel Threshold Model[J]. World Economics and Political Forum, 2017(5): 135-152. 